\title{
«La montaña y su impronta en la grandes tradiciones de sabiduría de la Antigüedad»
}

\author{
The mountains and their fingerprint on the great traditions of \\ Ancient Wisdom
}

\author{
MARÍA TEREsa RomÁn LÓPEZ*
}

\begin{abstract}
RESUMEN
ABSTRACT

Las grandes tradiciones de sabiduría de la Antigüedad albergan en su seno mitos, leyendas, cuentos, fábulas cuyo protagonista es la montaña. Factores geográficos, históricos, religiosos, místicos, simbólicos, mitológicos,

literarios, psicológicos, culturales... se dan cita en la montaña. En la mayoría de los pueblos de la tierra hallamos montañas sagradas y míticas: Sinaí, Kailâsa, Meru, Fuji Yama, Kuen-Iuen, Olimpo, Parnaso,

etc.

The great traditions coming from the ancient wisdom keep inside themselves a collection of myths, legends, tales, and fables whose hero is the mountain. A set of geographical factors, also and historical religious, mystics, mythological, literary, psychological, cultural, symbolical... come together on the mountain. In most of the peoples of the Earth, we find sacred and mythical: Mount Sinaí, Kailâsa, Meru, Fuji Yama, Kuen-Iuen, Olympus, Parnassus, and so on.

PALABRAS CLAVE: Montañas sagradas; montañas de China y Japón; Biblia; peregrinación; Kailâsa; Meru; Fuji-San; Kuen-Iuen; Olimpo; montañas míticas.

\section{KEYWORDS:}

Sacred mountains; Chinese and Japanese mountains; Bible; pilgrimage; Kailâsa; Meru; Fuji-San; Kuen-Iuen; Olympus; mythical mountains.
\end{abstract}

* Departamento de Filosofía de la UNED. Paseo Senda del Rey, 7. 28040 Madrid. E-mail: mroman@fsof.uned.es 


\section{INTRODUCCIÓN}

«La montaña es castigada por el huracán; mi cuerpo es castigado por el torbellino de las actividades exteriores. Así como la montaña permanece impasible, inquebrantable en medio de la tempestad, así mi cuerpo, "cerrando la puerta de los sentidos", puede abstenerse de actuar por manifestaciones reflejas de actividad, en tanto las percepciones y las sensaciones lo asaltan como un huracán".

"La montaña presta su suelo a la selva, que sumerge allí sus raíces y mil plantas viven en ellas... Caridad, don de sí mismo", piensa otro discípulo.

"Desprendimiento..." dice un tercero. "Las estaciones se suceden cubriendo la montaña con un manto verde o con un manto de nieve: ella lleva uno y otro con indiferencia".

Los maestros sonríen. Todo esto son pequeños razonamientos. Hay que dejarlos atrás.

Otro explica: "Surgida de la vasta tierra, siendo una con ella, siendo ella misma tierra, la montaña no debe considerarse como una cosa separada. Todas las formas - comprendiendo mi cuerpo — surgen del fondo común de todas las cosas (Kungji) y siguen a él ligadas. No son más que Kungji”.

El maestro común sonríe aún. Yo estoy a punto de decir que quizá este discípulo está en el buen camino, pero ya el lama ha pronunciado: "Meditad: no son teorías lo que hay que encontrar... Hay que ver..."»

A. David Néel, Iniciaciones e iniciados del Tíbet.

Las grandes tradiciones religiosas de nuestro planeta albergan en su seno mitos, leyendas, cuentos, fábulas que tienen como telón de fondo la montaña ${ }^{1}$; en ella se dan cita innumerables e importantes factores, a saber: geográficos (el volcán escupe fuego, algunas cimas se arropan con nieves perpetuas para dispensar el agua, fuente de la vida y el viento envuelve la imponente estructura pétrea y em-

1 «La Montaña es el vínculo entre la Tierra y el Cielo. Su cumbre única pertenece al mundo de la eternidad, y su pie se ramifica en contrafuertes múltiples que recorren el mundo de los mortales. Es el camino por el que el hombre puede elevarse hasta la divinidad y la divinidad se le puede revelar al hombre. Los patriarcas y los profetas del Antiguo Testamento ven al Señor cara a cara en lugares elevados. Ahí tenemos el Sinaí y el Nebo de Moisés; y, en el Nuevo Testamento, el Monte de los Olivos y el Gólgota. Incluso me parecía encontrar el antiguo símbolo de la montaña en las elaboradas edificaciones piramidales de Egipto y Caldea. Y, pasando a los arios, mencionaba esas oscuras leyendas de los Vedas que dicen que el soma, ese "licor" que es semilla de inmortalidad" reside, en su forma luminosa y sutil, "en la montaña". En la India, el Himalaya es el lugar donde moran Shiva, su esposa, "la Hija de la Montaña", y las "Madres" de los mundos, de la misma forma que en Grecia el rey de los dioses tenía su corte en el Olimpo. Precisamente en la mitología griega era donde me parecía a mí que se completaba el símbolo de la historia de la sublevación de los hijos de la Tierra, quienes, con sus naturalezas terrestres y con medios terrenales, intentaron escalar el Olimpo y poner en el Cielo sus pies de barro. ¿No era, por cierto, la misma empresa que pretendían los edificadores de Babel cuando, sin renunciar a sus ambiciones múltiples y personales, aspiraban a alcanzar el reino de lo Único impersonal? En la China, se hablaba de las "Montañas de los Bienaventurados"; y los sabios antiguos impartían enseñanza a sus discípulos al borde de los precipicios... ». R. Daumal, El monte análogo, Atalanta, Girona, 2006, pp. 19-20. 
puja hacia ella una corona de nubes plateadas ${ }^{2}$ que muestran su realeza), religio$\operatorname{sos}^{3}$, místicos ${ }^{4}$, simbólicos $^{5}$, literarios ${ }^{6}$, psicológicos, culturales ${ }^{7}$, históricos, etc.

2 «A medida que uno asciende los picos de los Himalayas y observa el océano cósmico de las nubes debajo de uno, se ven las murallas de interminables macizos rocosos y las hileras nacaradas de nubecillas. Detrás de ellas marchan los elefantes grises del cielo, las pesadas nubes del monzón. ¿Acaso no es esto un cuadro cósmico que nos llena de comprensión de alguna gran manifestación creadora?». M. Pallis, Cumbres y lamas, Sudamericana, Buenos Aires, 1946, p. 32.

3 En la Biblia, la primera parte de la tierra que surgió de las aguas caóticas del diluvio fue un monte. En el relato del diluvio, «el día veintisiete del séptimo mes se asentó el arca sobre los montes de Ararat» (Génesis 8,4). Esta creencia también aparece en el antiguo Egipto: «Igual que tantas otras tradiciones, la cosmogonía egipcia comienza con la aparición de un montículo sobre las aguas primordiales. La aparición de este "primer lugar" por encima de la inmensidad acuática significa la consolidación de la tierra, pero también la eclosión de la luz, de la vida y de la conciencia. En Hierápolis se identificaba el lugar llamado "la Colina de Arena", que formaba parte del templo del sol, con la "colina primordial" [...] El montículo inicial pasaba a ser muchas veces la montaña cósmica a la que ascendía el Faraón para salir al encuentro del dios Sol». M. Eliade, Historia de las Creencias y de las Ideas Religiosas, Cristiandad, vol. I, Madrid, 1978, p. 104.

4 «Desde los tiempos más remotos, en casi todas las civilizaciones, la montaña ha valido uniformemente como símbolo de los estados interiores trascendentes y como sede alegórica de naturaleza divina, de los héroes, en general, de seres transfigurados y llevados más allá de la condición humana; tanto es así que ascender las cumbres o ser arrebatado hacia ellas en los más variados mitos de la humanidad tradicional aparece según el valor de un misterioso proceso de superación, de integración espiritual, de participación en la "super-vida" olímpica y en la inmortalidad [...] El hombre antiguo no escogía al azar la montaña como medio de expresión simbólica de significados netamente trascendentes; a ello le indujeron razones de analogía, pero, además, un presentimiento de aquello mismo que la experiencia de la montaña puede sugerir a la parte más profunda de nuestro ser, una vez que ella haya sido adecuadamente realizada». J. Évola, Meditaciones de las cumbres, Ediciones Nueva República, Barcelona, 2003, pp. 63-64. Por su parte, Angelus Silesius afirma: «Soy una montaña en Dios y yo mismo he de escalarme hasta que Dios no me muestre su amado rostro». El peregrino querúbico, Siruela, Madrid, 2005, p. 106.

5 «El simbolismo de la montaña es múltiple; contiene el de la altura y el del centro. En cuanto alta, vertical, elevada y próxima al cielo, participa del simbolismo de la trascendencia; en cuanto centro de las hierofantas atmosféricas y de numerosas teofanías, participa del simbolismo de la manifestación. Es así el encuentro del cielo y la tierra, la morada de los dioses y el término de la ascensión humana. Vista desde lo alto, aparece como la punta de una vertical; es el centro del mundo; vista desde abajo, desde el horizonte, aparece como la línea de una vertical, el eje del mundo, pero también la escala, la pendiente a escalar». J. Chevalier y A. Gheerbrant, Diccionario de los símbolos, Herder, Barcelona, 1986, p. 722.

6 Víctor Hugo menciona una montaña llamada Patmos: «Todo hombre lleva en sí un Patmos. Es libre de subir o de no subir a la temible cumbre del pensamiento, desde la que se distinguen las tinieblas. Si no sube, el hombre permanece en la vida, en la conciencia, en la virtud y en la fe ordinarias. Para estar tranquilos interiormente, sin duda lo más conveniente es este estado. Pero si el hombre sube a la cumbre, queda allí preso, porque se le aparece el oleaje del prodigio y nadie ve impunemente ese océano. En lo sucesivo, su pensamiento se dilata y se agranda, pero flota. El que sube a la cúspide se convierte en soñador y por un lado toca con el poeta y por el otro con el profeta. En este caso cierta cantidad de sí mismo pertenece a la sombra. Lo ilimitado penetra en su vida, en su conciencia, en su virtud y en su filosofía. Aparece extraordinario a los otros hombres, porque tiene medida diferente y deberes que ellos no conocen. Vive en la oración difusa y se aproxima a una certeza indeterminada, que él llama Dios. Distingue este crepúsculo suficiente de la vida anterior y lo bastante de la vida ulterior, para coger los dos extremos del hilo sombrío y atar con él el alma. El que ha bebido beberá y el que ha soñado soñará. Se obstina en permanecer junto al abismo que le atrae, junto a lo inexplorado. Siente desinterés por la tierra y por la vida, contempla la entrada que conduce a lo prohibido, se esfuerza en palpar lo impalpable, en ver lo invisible, va y viene, se inclina, se abalanza, da un paso, después dos, y así penetra en lo impenetrable y en las dilataciones sin límites de la meditación infinita». W. Shakespeare, Aguilar, Madrid, 1959, pp. 275-276.

7 Las montañas suelen ser el prototipo de lugares donde expresar culto que combinan la devoción sagrada y la atracción telúrica. Sin embargo, el mundo actual ha dejado atrás los referentes que hacían de una determinada montaña un ámbito singular, aunque siga valorándola de un modo especial pero ya muy alejado de los significados e interpretaciones de antaño, desfiguradas por la inclusión de sucesivas interpretaciones. 
En medio de un silencio sobrecogedor como pocos y de una soledad inquietante, se yergue majestuosa, serena e imperturbable la montaña: santuario pétreo, centinela misterioso, gigante coronado de nieve - frecuentemente visitado por un ejército de celajes-, mansión de dioses, espíritus, genios ${ }^{8}$ y criaturas extrañas, morada de los muertos, "alma vieja», un eje que conecta el Cielo con la Tierra, lugar de inspiración y meditación ${ }^{9}$, uno de los sitios preferidos para dar culto a las deidades y ofrecer sacrificios ${ }^{10}$, enclave de pactos divinos, lugar de prédi$\mathrm{ca}^{11}$, en resumen, un espacio sagrado por excelencia ${ }^{12}$ : «La montaña, por estar más cerca del cielo, es sagrada por dos conceptos: por un lado, participa del simbolismo espacial de la trascendencia («alto», «vertical», «supremo», etc.), y por otro, es el dominio por excelencia de las hierofantas atmosféricas, y en su virtud, la morada de los dioses. Todas las mitologías tienen una montaña sagrada [...] Todos los dioses celestes tienen en sitios altos lugares dedicados a su culto. Los valores simbólicos y religiosos de las montañas son innumerables» ${ }^{13}$.

No es de extrañar pues que las cumbres de las montañas hayan sido visitadas por grandes figuras de la historia de las tradiciones religiosas: Abraham, Moisés, Elías, David, Salomón, Jesús, Milarepa, el Buddha, Mahinda, etc.

8 La montaña a veces está poblada de entidades temibles que impiden acercarse a la cima.

9 «Milarepa llegó a Nya Non Tsar Ma, paso a la montaña nevada de Lashi, donde la gente de Tsar Ma tenía una fiesta y bebía. En sus charlas alguien dijo: “¿Sabían ustedes que actualmente vive un gran yogui llamado Milarepa? Vive siempre solo en las montañas nevadas, en lugares remotos e inhabitables observando disciplinas ascéticas que nadie más que un perfecto budista puede lograr». O. Kochen (tr.), Cantos de Milarepa, Centro Yoga Universal Ciudad de México y Editorial Yug, vol. I, México, 1981, p. 27.

10 La costumbre de dar culto y ofrecer sacrificios a las deidades sobre las montañas estaba bastante extendida en las religiones antiguas. Sobre el monte Safón, Anat construyó un templo para Baal, según la mitología ugarítica. Al norte de Mesopotamia se eleva el monte Nisir, donde Utnapishtim, ofreció un sacrificio a los dioses: «Cinco días, seis días el monte Nisir retuvo inmóvil al barco [...] Habiendo dejado salir todo a los cuatro vientos, ofrecí un sacrificio, puse una ofrenda en la cima de la montaña y dispuse frente a siete y siete recipientes en cuyas concavidades vertí ácoro, cedros y mirto». F. Lara (ed.), Poema de Gilgamesh, Tecnos, Madrid, 2001, p. 171. A punto está Abraham de ofrecer a su hijo en sacrificio a Yavé en un monte de la tierra de Moriah: «Anda, coge a tu hijo, a tu unigénito, a quien tanto amas, a Isaac, y ve a la tierra de Moriah, y ofrécemelo allí en holocausto sobre uno de los montes que yo te indicaré» (Génesis 22,2). En China, las montañas y las corrientes de agua eran potencias sagradas a las que se ofrecían sacrificios desde la más remota antigüedad. En Grecia, Hermes tenía un templo en la cumbre del monte Cilene, y Apolo el suyo sobre el monte Figaleia. Al sur del monte de los Olivos, el rey Salomón erigió santuarios para sus mujeres extranjeras dedicados a Astarté, "la abominación de los sidonios"; Camos, "la abominación de los moabitas" y a Milcom, "la abominación de los amonitas" (II Reyes 24,13 ), en los que quemaban perfumes y ofrecían sacrificios (I Reyes 11, 7-8), de ahí el nombre de "Monte de la Profanación". Los cultos paganos se celebraban frecuentemente en lugares altos. Por esta razón el judaísmo, y tras él el cristianismo primitivo, esperan una nivelación o una desaparición de las montañas. Cuando Dios saque a su pueblo del exilio, allanará las escarpaduras: «Que se rellenen todos los valles y se rebajen todos los montes y collados" (Isaías 40,4). El fin del mundo entrañará en primer lugar el derrumbamiento de las montañas: «Huyeron todas las islas, y las montañas desaparecieron» (Apocalipsis 16,20).

11 En el «Monte del Buitre», situado en las proximidades de la ciudad de Râjagriha, el Buddha predicó el "Sutra del loto», uno los textos más importantes de la corriente budista Mahâyâna. Recordemos asimismo, el "Sermón de la montaña", en la tradición cristiana.

12 Véase J.-P. Roux, Montagnes sacrées. Montagnes mythiques, Fayard, París, 1999.

13 M. Eliade, Tratado de historia de las religiones. Morfología y dialéctica de lo sagrado, Cristiandad, Madrid, 1981, p. 117. 
Escalar la montaña es un rito de iniciación, un encuentro con uno mismo, una búsqueda de alimento espiritual, una gran oportunidad de entrar en la «vida adulta del alma». En palabras de Paul Brunton: «Los abruptos senderos del Himalaya son iguales a los abruptos senderos de la vida misma: Pero yo me aventuro por el difícil camino con una música resonando en mis oídos [...] Estoy cabalgando, no solamente en los Himalayas, sino que voy hacia los cielos. He olvidado un mundo sólo para encontrar otro» ${ }^{14}$.

En los recuerdos mitológicos de la mayoría de los pueblos de la tierra hallamos montañas sagradas ${ }^{15}$ y mágicas ${ }^{16}$. No son pocas las montañas donde los pueblos antiguos veían o presentían a las divinidades, apareciendo y ocultándose alternativamente bajo el grácil cendal de los celajes: Montmartre en Francia; Montserrat en España; en el mundo judeo-cristiano, Sinaí, Moria, Nebo, Sión, Tabor, Carmelo ${ }^{17}$, etc.; en el Tíbet, el Kailâsa, residencia del dios hindú Shiva, uno de los poderosos miembros de la trinidad hindú18; además del Kailâsa y del mítico Meru, la India ha incorporado otras montañas sagradas, por ejemplo, el Arunachala rodeado de varios templos, como el de Tiruvanamalai, donde vivió y murió Ramana Ma-

14 P. Brunton, Una ermita en los Himalayas, Kier, Buenos Aires, 1980, p. 21.

15 En el ámbito judeo-cristiano la montaña sagrada encuentra diversos ecos: «Las bendiciones de tu padre sobrepasan a las bendiciones de los montes eternos» (Génesis 49,26); «Tu justicia es como los montes de Dios» (Salmos 36,7); «Me instalaré en el monte santo» (Isaías 14,13); «El día en que fuiste creado te pusieron junto al querube colocado en el monte de Dios» (Ezequiel 28,14); «Pero sucederá a lo postrero de los tiempos que el monte de la casa de Yavé será confirmado por cabeza de los montes, y será ensalzado sobre los collados, y correrán a él todas las gentes, y vendrán muchedumbres de pueblos, diciendo: Venid, subamos al monte de Yavé, a la casa del Dios de Jacob» (Isaías 2,2); «Pero al fin de los tiempos el monte de la casa de Yavé se alzará a la cabeza de los montes, se elevará sobre los collados, y los pueblos correrán a él, y vendrán numerosos pueblos diciendo: Venid, subamos al monte de Yavé, a la casa del Dios de Jacob» (Miqueas 4,1); "Yavé, saliendo del Sinaí, vino a Seir a favor nuestro. Resplandeció desde la montaña de Farán. Desde el desierto de Cadés, con los rayos en su diestra» (Deuteronomio 33,2). También la India cuenta con importantes montañas sagradas: Kailâsa («Montañade-los-placeres»), Montaña Parvata, Deva-giri («Montaña-de-los-dioses»), Puspa-giri («Montaña-Florida»), Mandara («Montaña-lenta»), Himavat («Monte-nevado»). Véase A. Daniélou, Dioses y mitos de la India, Atalanta, Girona, 2009, pp. 258, 411, 299, 396, 177, 233, 239.

16 «Las montañas son lugares mágicos a los que uno se acerca con temor. Allí residen los dioses, allí se retiran los sabios para recibir la inspiración divina. En una montaña Moisés conversó con Dios. Shiva reside en una montaña. Su esposa es la Dama de la montaña. Del mismo modo, Dionisos es venerado en el monte Ida. Diktynna es la diosa del monte Dikte. El monte Olimpo se hizo, para los griegos, la mansión de los dioses. Antes moraban en el monte Athos, el antiguo akte. Athos, hijo de Poseidón, arrancó ese bloque montañoso de Tracia, donde se encontraba, y lo lanzó a su actual emplazamiento. Athos siguió siendo la montaña sagrada de Dionisos [...] Skanda, cuyo luto está prohibido a las mujeres, se retiró a una montaña. Esta tradición se ha preservado en el monte Athos, antiguo lugar de retiro de eremitas dionisíacos. Según la leyenda, transpuesta a términos cristianos, la Virgen bendijo la montaña, destruyó las imágenes de los antiguos dioses, la declaró su jardín y la prohibió a las demás mujeres [...] El Kailâsa, montaña en la que se encuentra el paraíso de Shiva». A. Daniélou, Shiva y Dionisios. La Religión de la Naturaleza y del Eros, Kairós, Barcelona, 1987, p. 189.

17 La Biblia menciona explícitamente algunas montañas: los Olivos (II Samuel 15,30), el Sinaí (Éxodo 19,16-18), el Sión (Apocalipsis 21,10), etc. En cambio, no es fácil decir qué montañas se trata en los casos siguientes: las tentaciones (Mateo 4,8; Lucas, 4,5), la transfiguración (Mateo 17,1-9), el lugar del Sermón de la Montaña (Mateo 5,1; 8,1; Lucas 6,17), la de la vocación de los discípulos (Marcos 3,13; Lucas 6,12), las montañas del Apocalipsis (Apocalipsis 8,8; 16,20; 17,9), las montañas evocadas por Jesús en su enseñanza (Mateo 5,14; 17,20; 21,21; Marcos 11,23; I Corintios 13,2), la montaña donde Jesús citó a sus discípulos (Mateo 28,16), la montaña donde se sienta Jesús (Mateo 15,29; Juan 6,3).

18 Constituida por Brahma («el creador»), Vishnu («el conservador») y Shiva («el destructor»). 
harshi, el gran místico hindú; Fuji Yama o Fuji-San en Japón; en China, el Kuenluen, origen de muchas leyendas extrañas y en la antigua Grecia, el Olimpo y el Parnaso, solo por mencionar algunos.

Dentro de las restricciones a las que nos somete el espacio del cual disponemos, vamos a intentar ofrecer, en este artículo, una visión lo más completa y comprehensiva posible de algunos de los diferentes roles que ha jugado la montaña, uno de los grandes activos simbólicos, en las más importantes tradiciones de sabiduría de la Antigüedad.

\section{MONTAÑAS SAGRADAS}

Las montañas ocupan un lugar muy especial en la geografía simbólica de la mayoría de las tradiciones religiosas de nuestro planeta. Para unas son lugares de visión y revelación. El Sinaí, donde Moisés se encontró con Yavé cara a cara, es uno de los ejemplos más llamativos de una montaña de revelación (Éxodo 19,16). Otras tradiciones consideran que las montañas son manifestaciones geográficas de lo divino. En la mitología griega, las montañas — hijas de la Tierra- eran consideradas lugares sagrados y adoradas, a menudo, como divinidades: Cibeles, por ejemplo, era una diosa de la montaña. En la tradición hindú, Parvati no sólo es el símbolo del éter y de la fuerza, sino también una diosa de la montaña; es además la consorte de Shiva, el cual es por su parte «el señor de las montañas». En la mitología japonesa hallamos diversas divinidades relacionadas con la montaña: OYama-Tsu-Mi, dios principal y señor de las montañas; Naka-Yama-Tsu-Mi, el «dios de las Pendientes montañas»; Ha-Yama-Tsu-Mi, el «dios de las Laderas inferiores»; Masaka-Yama-Tsu-mi, «dios de la Pendiente abrupta» y Shigi-YamaTsu-Mi, «dios del Pie de la montaña». Los antiguos egipcios se referían a Atum como «colina» y hablaban del monte el Set Amentet: «atravesado por un camino, siguiendo el cual los seres destinados a la inmortalidad «solar» llegaban a la «tierra del triunfo» donde — según una inscripción jeroglífica- «los jefes que presiden el trono del gran dios proclaman vida y potencia eternas para ellos» ${ }^{19}$; el principal dios sumerio, Enlil, tenía por sobrenombre «Gran Monte». Los servidores del rey de Siria decían del Dios de los israelitas que era «un dios de monte» (I Reyes 20,23).

No faltan las tradiciones que creen que ciertas montañas reales o míticas están situadas en el "ombligo de la tierra», en el centro del Mundo: el Meru o Sumeru, en el hinduismo y el budismo; el Borobudur (construido en forma de montaña) situado en Java central; el «Monte de los Países» y el zigurat en Mesopotamia; Garizim, Tabor y Gólgota en la tradición judeo-cristiana y, finalmente, la montaña cósmica de Qâf en la tradición musulmana. En efecto, como el centro del mundo, enlazando la tierra y el cielo y sujetando las cuatro direcciones cardinales, la montaña representa en muchas ocasiones un axis mundi (el centro del mundo).

19 J. Évola, ob.cit., p. 57. 
La peregrinación constituye una parte esencial de la mayoría de las tradiciones religiosas y algunas importantes rutas de peregrinación tienen como destino la montaña ${ }^{20}$; una de éstas es la que lleva a algunas personas a atravesar la gran cadena himaláyica hasta el Kailâsa (también llamada por los tibetanos «Montaña de la Nieve Preciosa», «Joya de las nieves» o «Joya de hielo»), una imponente montaña, envuelta en una trama de mitos. Sagrada para los hindúes, los budistas, los jainas y los bonpos ${ }^{21}$, se identifica a veces con el monte Meru, la montaña axial que es el centro del mundo y que está ubicada en el Tíbet. Shiva y su esposa Parvatî («Hija de la montaña»), moran en el Kailâsa. En el Shiva Purâna leemos:

«El Kailâsa es la bienaventuranza y espléndida montaña donde reside Shiva. Allí viven los Kinnaras (de pies de cabra), los Apsaras (ninfas), los Siddhas (elegidos) y demás espíritus celestiales. La montaña es de gran altura, con resplandecientes cimas sembradas de piedras preciosas multicolores y otros minerales. Se encuentran allí toda clase de árboles y lianas, gacelas, corzas, ciervas y miles de pájaros. Las ninfas juegan allí con sus amantes, en los manantiales y los estanques, en las grutas y cumbres. Los árboles tienen reflejos plateados. Hay numerosos animales, tigres y demás pero no son feroces. La naturaleza es espléndida y produce asombro y admiración. El Ganges, nacido en la montaña, lo santifica y purifica todo... No lejos se encuentra Alakâ, la ciudad de Kubera (el guardián de los tesoros) y el «jardín de los perfumes» (Saugandhika) con todas las variedades de árboles. Los murmullos que de allí salen forman una maravillosa música. Alrededor de la montaña circulan los ríos Nandâ y Alakandandâ cuya sola vista borra toda falta. Las ninfas bajan para beber en sus aguas. Agotadas por los juegos amorosos, se refrescan. Más lejos está el Pippala, la higuera bajo la que Shiva practica el Yoga. No hay nidos en ella. Produce una espesa sombra. Es magnífica y sagrada»22.

Con forma de pirámide, el Kailâsa está suspendido sobre una llanura elevada donde se hallan dos lagos sagrados, el Manasarovar y el Rakastal. Cuatro ríos tienen su nacimiento en esta llanura: el Brahmaputra al este, el Karnali al sur, el Sutlej al oeste y el Indo al norte. El conjunto forma un mandala ${ }^{23}$ natural en el que el

20 La peregrinación a montañas sagradas simboliza el apartarse gradualmente del universo de la realidad consensuada y la ascensión espiritual. Así, por ejemplo, el místico español San Juan de la Cruz (1542-1591) llama a su camino hacia Dios la «subida al monte Carmelo». En la segunda parte de su periplo a través de «los tres mundos», Dante, el gran poeta italiano, refiere la ascensión de la Colina del Purgatorio, en cuya cima sitúa el «Jardín del Edén», el «Paraíso Terrenal» que es precisamente la condición de Adán antes de la Caída.

21 Representantes del Bon tibetano: «Un ideario, un cúmulo de territorios mentales, de una asombrosa riqueza, para algunos superior a la del Budismo. Y desde luego si consideramos el Budismo tibetano como el término de un largo proceso evolutivo, sin el Bon, nunca hubiera llegado a ser». I. Preciado, Svastika. Religión y magia en el Tíbet, Oberón, Madrid, 2003, p. 31.

22 A. Daniélou, ob.cit., pp. 190-191.

23 «Mandala significa cerco.

Ante todo el mandala delinea la superficie consagrada y la preserva de la invasión de las fuerzas disgregadoras simbolizadas en ciclos demoníacos. Pero es mucho más que una simple superficie consagrada y conservada pura para fines rituales y litúrgicos. Es, ante todo, un cosmograma, el universo entero en su esquema esencial, en su proceso de emanación y reabsorción: el universo no sólo en su inerte extensión espacial, sino como revolución temporal; y una y otra como proceso vital que se desarrolla por un principio esencial y rota alrededor de un eje central, la montaña Sumeru, el axis mundi sobre el que se apoya el cielo y que hunde las bases en el subsuelo misterioso. Esta es una concepción panasiática a la que contribuyeron a dar claridad y precisión las ideas cosmográficas expresadas 
Kailâsa ocupa el centro. La región es recorrida por peregrinos que efectúan la circunvalación alrededor de la montaña en el curso de varios días. Veamos a continuación un fragmento de la narración de Anagarika Govinda sobre su peregrinación al Kailâsa:

«El peregrino se acerca a la montaña desde las doradas llanuras del Sur, desde el mediodía de la vida, en el vigor y la experiencia plena de la misma. Entra en el rojo valle de Amitâbha a la suave luz del sol poniente, atraviesa el portal de la muerte entre un oscuro valle al norte y otro al Este, lleno de colorido, al ascender el formidable Dölma-La, el Paso de Târâ, la Salvadora, y desciende, como un ser recién nacido, hacia el verde valle de Aksobya al Este del Kailas, donde el santo poeta Milarepa compuso sus himnos, y desde donde el peregrino nuevamente sale a las abiertas y soleadas llanuras del sur, asignadas al Dhyâni-Buda Ratnasambhava, cuyo color es el del oro.

El peregrino que en realidad caminó por las «arenas doradas» del Sur siente que aquí está moviéndose a través de un gigantesco Mandala, creado milagrosamente por la naturaleza, en el que las formas y los colores le hablan en el lenguaje simbólico con el que las experiencias de meditación se han transmitido desde los albores de la humanidad.

Al entrar en el estrecho valle del lado Oeste del Kailas, el lugar asignado de Amitâbha, cuyo color es el rojo, se encuentra en un cañón de rocas rojizas, adornadas con elaboradas cornisas, repisas y pilares; la apariencia del cañón es tan arquitectónica que el peregrino siente como si caminase entre hileras de templos gigantescos. Y por encima de todo esto aparece deslumbrante la cúpula helada del Kailas» 24 .

Una de las rutas más famosas de peregrinación es la cumbre cónica del volcánico Monte Fuji-san o Fujiyama, una de las montañas que gozan de mayor veneración, cuyas laderas miles de peregrinos recorren anualmente hasta el borde del cráter, o bien ofrecen sacrificios en uno de los innumerables santuarios shintoístas ${ }^{25}$ que se encuentran al pie del monte sagrado japonés.

en el zikurrat asirio-babilónico, luego reflejadas en el esquema de la ciudad imperial de los reyes iranios y después en la imagen ideal del palacio del chakravartin, el monarca universal de las tradiciones indias. Dichas equivalencias y teorías cosmográficas de origen asirio-babilónico se amoldan, sin embargo, a intuiciones primitivas según las cuales el sacerdote o el mago delimitan sobre la tierra una superficie sacra: ésta no sólo representa una defensa desde la línea que la termina, una protección de las fuerzas arcanas que amenazan la superficie sagrada del lugar o la integridad psíquica del que cumple la ceremonia, sino también, por transposición mágica, el mundo mismo; allí el celebrante se identifica, poniéndose en el centro, con las fuerzas que regulan el universo y recoge en sí la potencia taumatúrgica». G. Tucci, Teoría y práctica del mandala, Dédalo, Buenos Aires, 1975, pp. 35-36.

24 A. Govinda, El camino de las nubes blancas, Eyras, Madrid, 1977, p. 312.

25 Shintoismo quiere decir "vía de los kami», y está muy relacionado con una rica y compleja estructura de concepciones, ideas, ritos e instituciones sagradas, tan hondamente enraizado en la historia de Japón, que se convirtió en un foco de inspiración para ciertos aspectos culturales de gran significación. Se trata de un fenómeno poliédrico que aparece en la humilde tradición de las aldeas y en los cultos campesinos, y que también forma parte de una institución religiosa a nivel nacional muy unida a la ideología estatal. 
Una de las montañas sagradas de Sri Lanka, la antigua Ceilán, es el Mahintala ${ }^{26}$, donde se detuvo Mahinda, hijo del rey Ashoka (tercer monarca de la dinastía maurya que reinó en la India desde 272-236 a.C.), elegido por el monarca para guiar la misión a Sri Lanka y que dio por resultado la conversión al budismo del rey cingalés Devânam-piya Tissa. En la actualidad, hay un templo en la cima donde puso el pie Mahinda.

Otra de las montañas sagradas de Sri Lanka es el «Pico de Adán» o Monte Sirip da («santo pie», «pie auspicioso»), uno de los lugares más antiguos de peregrinación. Allí se halla una depresión en la roca en forma de huella de un pie humano gigantesco. Los budistas afirman que es una huella que dejó el Buddha cuando utilizó sus poderes meditativos para volar a la isla en un viaje de enseñanza. Por su parte, los hindúes veneran la misma huella como la de Shiva; los musulmanes como la de Adán y los cristianos, como la del apóstol Tomás. En $A$ través del Islam, el gran viajero musulmán Ibn Baț̣uța recuerda la subida al Pico de Adán:

«Este monte Sarandīb [o Pico de Adán] es una de las montañas más altas del mundo. Ya lo habíamos visto desde el mar cuando aún estábamos a nueve jornadas de distancia de Ceilán, y, mientras íbamos subiendo por él, quedaban nubes por debajo de nosotros que nos estorbaban la vista de su base [...] En el monte hay dos caminos que van al Pie de Adán [al-Qadam], llamado uno de ellos Camino del Padre [T Tarìq Bāba] y el otro, Camino de la Madre [Ṭarīq Māmā] , es decir, de Adán y Eva, ique la paz sea con ellos! El Camino de la Madre es una senda fácil, por la que regresan los romeros, pero si alguno la usa para subir, se considera que no ha hecho la peregrinación. El Camino del Padre, sin embargo, es duro y de áspera subida [...] La huella del Santo Pie, el Pie de nuestro padre Adán, a quien Dios bendiga y salve, se halla en una roca negra que se alza en un espacioso lugar. El Santo Pie está hundido en la piedra, en una especie de hoyo, y tiene una longitud de once palmos» ${ }^{27}$.

\section{MONTAÑAS DE CHINA Y JAPÓN}

El culto a las montañas sagradas ha ocupado un lugar muy importante en la religiosidad china más antigua. Las montañas eran consideradas garantes del orden cósmico, similar al que los emperadores ejercían en el seno de la sociedad. Bajo la dinastía Zhou, el emperador estaba encargado de los sacrificios a los cinco Picos sagrados ( $W u$ Yue); éstos, emplazados en las cuatro esquinas del espacio y en el centro, eran etapas obligatorias donde el emperador debía detenerse para hacer

26 «La leyenda cuenta que Mahinda se apareció milagrosamente, con todo su séquito, al rey Tissa cuando éste se encontraba cazando en una montaña a trece kilómetros al este de Anuradhapura -la montaña que hoy se llama Mihin-tale-, «el lugar donde Mahinda se apareció». El rey quedó tan impresionado por la aparición y por el comportamiento de sus inesperados visitantes que les ofreció enseguida una posición prestigiosa, a la vez que él mismo adoptaba la fe y los principios que predicaban, imitado por la corte y el pueblo». J. Gómez (ed.), Śri Lanka. La isla sagrada del budismo, Orbis y Montena, Madrid, 1985, p. 10.

27 Ibn Batțuța, A través del Islam, Alianza Universidad, Madrid, 2002, pp. 689 y 690. 
sacrificios cuando emprendía sus viajes rituales. Cada uno de estos picos se identificaba con una determinada deidad: «Los Señores de las Cinco Montañas (Wu-yueh Ti-chun) son los guardianes de las cinco montañas sagradas de China: Hua-shan en el oeste, T'ai-shan en el este, Heng-shan en el sur (en Hunán), Heng-shan en el norte (en Shansi) y Sung-shan en el centro ${ }^{28}$. Asimismo, el budismo chino cuenta con los denominados "Cuatro Montes de Gran Fama», célebres lugares de peregrinación, que se asociaron con las cuatro direcciones cardinales y cuatro importantes bodhisattva: Guanyin (Avaloliteshvara), Wenshu (Mañjushrî), Puxian (Samantabhadra) y Dizan (Kshitigarbha) ${ }^{29}$. Según la tradición popular, los bodhisattvas asociados con estas montañas aparecerían no sólo en los templos, sino que tomarían forma humana y se presentarían como mendigos o monjes ancianos a los peregrinos por el camino.

Además de las montañas anteriores, ocupaban el espacio imaginativo de las gentes que buscaban la inmortalidad otras montañas fabulosas. El Lie zi, uno de los grandes textos del taoísmo filosófico, cuenta la historia de las islas de los bienaventurados: «Al este de Bohai, a no sé cuántos millones de li, existe un gran abismo, un enorme valle sin fondo. Se llama Gui xu. Todas las aguas afluyen a él, las aguas de los ocho límites y las nueve ubicaciones (todas las aguas de la tierra), y las de la Vía Láctea [...] En medio se encuentran cinco montañas. La primera se llama Dai yu, la segunda Yuan jiao, la tercera Fang hu, la cuarta Ying zhou y la quinta Peng lai [...] Todos los edificios y templos que en ellas hay son de oro y jade; las aves y bestias, todas de colores puros y muy vivos; árboles de perlas y gemas se extienden en frondosos bosques, y las flores y frutos, de exquisito sabor, preservan a quien los come de la vejez y la muerte. Sus habitantes son todos Inmortales y Sabios» 30 .

La montaña mítica del oeste es el Kuen-luen o Kunlun, «montaña cristalina» de China occidental, que separa el Tíbet de Sinkiang; su nombre figura por primera vez en el capítulo «Tributo de Yu» del Chu King. Según la religiosidad china: «Los Inmortales viven en el Kunlun, la montaña del centro del mundo alrededor de la cual giran el Sol y la Luna, donde reina la Dama Reina de Occidente (Xiwang$\mathrm{mu}$ ), con su esposo el Señor Rey de Oriente (Dongwanggong) [...] Los jardines de Xiwangmu están situados en la cima del Kunlun. Allí crece el Melocotonero, cuyos frutos confieren la inmortalidad» ${ }^{31}$. Asimismo en Viaje al oeste. Las aventuras del rey mono, un texto anónimo chino del siglo XVI, encontramos la «Montaña de las Flores y Frutos»; al parecer su belleza era tal que el rapsoda la describió así:

«Su majestad compite con la serenidad del mismo océano, como si fuera el emperador de los mares. Las olas rompen contra su costado, como montañas de plata que el golpe transforma en diminutas escamas de nieve, lanzando a los peces

${ }^{28}$ E. Wong, Taoísmo, Oniro, Barcelona, 1997, p. 177.

29 «Guanyin reside al Este, en la isla de Putuo (Zhejiang) [...] Wenshu, al Norte sobre el Wutaishan (Shanxi); Puxian, al Oeste, sobre el Emeishan (Sichuan); y Dizang, al Sur sobre el Jiuhuashan (Anhui)». H. Maspero, El taoísmo y las religiones chinas, Trotta, Madrid, 1999, p. 139.

30 I. Preciado (ed.), Lie Zi, El Libro de la Perfecta Vacuidad, Kairós, Barcelona, 1994, p. 88.

31 H. Maspero, ob.cit., p. 211. 
«La montaña y su impronta en la grandes tradiciones de sabiduría de la Antigüedad»

contra las rocas y sacando de su sueño de profundidad a las serpientes marinas. En su parte suroccidental se aprecian llamativas planicies cargadas de serenidad, mientras que al este todo es abruptez de picos que se arrojan con mal disimulada fiereza en el mar. Los que permanecen, orgullosos, en tierra seca se visten, a la hora del crepúsculo, de tintes violáceos, que esconden su inaccesible bravura pétrea. En sus cumbres cantan, emparejados, los fénix, mientras que a su pie descansan los solitarios unicornios. Por doquier se oye el lamento de los faisanes, que buscan, desesperados, las cuevas en las que habitan los dragones. Toda la isla está poblada de extraordinarios animales que muy pocas veces se ven en otras partes, como los longevos ciervos, las inmortales zorras, las divinas lechuzas o las cigüeñas de negro plumaje. En ese lugar extraordinario la hierba nunca se seca ni las flores se marchitan. La primavera es allí eterna y adonquiera que se dirija la mirada puede verse el verdor de los cipreses y pinos, aliados incondicionados de la vida. Los melocotoneros están siempre en flor, las viñas se rompen bajo el peso de su propio fruto, la hierba de los pastos se mantiene siempre fresca y los bambúes alcanzan tales alturas que a veces llegan a frenar la loca carrera de las nubes. Éste es, en verdad, el privilegiado lugar donde el Cielo se apoya y la Tierra descansa de sus muchas fatigas, un paraíso en el que convergen más de cien ríos» ${ }^{32}$.

Desde la más remota antigüedad, las montañas han sido consideradas un espacio sagrado en el universo religioso japonés; esto se refleja en la presencia de los «santuarios de montaña» y de los «santuarios en las aldeas al pie de una montaña». Ya sea por motivos religiosos ya sea por motivos geográficos (en un país tan montañoso como Japón el espacio disponible es muy escaso) o ambos, la montaña ha sido el lugar de enterramiento por excelencia. Los primeros montículos funerarios parecen haber sido las colinas levemente acondicionadas. Posteriormente, recibirán el nombre de yama que significa montaña. Muchas montañas se han convertido en los centros privilegiados de las creencias relacionadas con la muerte y se consideran sobre todo lugares de residencia de los muertos, por ejemplo los montes Kôya, Tate, Osore, etc. Asimismo, la montaña ha conservado en las tradiciones populares un lugar de privilegio en los funerales y en los ritos funerarios.

El concepto de la montaña sagrada como reino de los muertos, lugar de paso entre este mundo y el otro, o de encuentro entre los vivos y los muertos, y la idea de que las montañas son el dominio de los espíritus, de las divinidades, o un territorio de prácticas y ascesis para los chamanes representan la base sobre la cual ha podido establecerse el shugendô: "Yamabushi ("los que duermen en las montañas", llamados también shugenja): esa palabra designa a unos ascetas monjes o laicos y se refiere a una de las formas más singulares de las creencias populares japonesas, el shugendô. Estos yamabushi pueden ser laicos o religiosos; practicaron en el pasado y aún practican hoy en cierta medida la ascensión a montañas sagradas, en determinados momentos del año; y allí, en lo alto, se entregan a ejercicios religiosos de naturaleza psico-física, adquiriendo así fuerzas sobrenaturales que les cualifican más tarde como exorcistas [...] En cuanto al shugendô, es "el ca-

32 E.P. Gatón e I. Huang-Wang (eds.), Viaje al oeste. Las aventuras del rey mono, Siruela, Madrid, 2003, pp. 56-57. 
mino (el método, dô) para adquirir por la práctica de ejercicios mágico-religiosos (shu), en las montañas, fuerzas sobrenaturales que otorgan poderes milagrosos (gen)» 33

\section{MONTAÑAS DE LA BIBLIA}

Las páginas de la Biblia están profusamente salpicadas de referencias a montañas. El Sinaí, la montaña bíblica por excelencia, a veces llamada Horeb (1Reyes 19,8), «monte de Dios» (Éxodo 3,1) o sencillamente «la montaña» (Éxodo 19,2-3) situada, según la tradición, en la parte meridional de la península del mismo nombre, ha sido el escenario de diversos encuentros entre Moisés y Yavé. Cuando Moisés llegó con el rebaño de su suegro al monte Horeb y quiso contemplar de cerca el prodigio de la zarza ardiente, Yavé le dijo: «No te acerques. Quita las sandalias de tus pies, que el lugar en que estás es tierra santa» $(3,5)$. Y poco después añadió: "Cuando hayas sacado de Egipto al pueblo, sacrificaréis a Dios sobre este monte» $(3,12)$. El pueblo de Israel, después de la arriesgada aventura que supuso la salida de Egipto, llegaron al desierto y acampó frente a la «Montaña de Dios»: «Subió Moisés a Dios, y Yavé le llamó desde lo alto de la montaña» $(19,3)$. Tres días después, Moisés sacó al pueblo del campamento para ir al encuentro de Yavé, y se colocaron al pie de la montaña sagrada: «Todo el Sinaí humeaba, pues había descendido Yavé en medio del fuego, y subía el humo, como el humo de un horno» (19,16-18). Moisés subió a la cumbre y allí recibió las «tablas de piedra, escritas por el dedo de Dios» (Éxodo 31,18). El profeta Elías también va a ser testigo de la manifestación de Dios en el monte Horeb: «Díjole Yavé: "Sal afuera y ponte en el monte ante Yavé» (I Reyes 19,11). «Levantóse pues; comió y bebió, y anduvo con la fuerza de aquella comida cuarenta días y cuarenta noches hasta el monte de Dios, Horeb» (I Reyes 19,8).

El Monte Carmelo es una franja montañosa calcárea de 20 kilómetros de longitud y 500 metros sobre el nivel del mar, continuación de la cordillera de Samaria en dirección noroeste, bajo la cual fluye el torrente Cisón (I Reyes 18,40). Era el límite meridional del territorio de Aser (Josué 19,26), y lugar en el territorio de la tribu de Judá (Josué 15,55), al sur de Hebrón. Desde la cima del Carmelo se divisa el Mediterráneo (Jeremías 46,18). Tras haber derrotado a los amalecitas, Saúl erigió allí un monumento: «Y levantándose de mañana para ir al encuentro de Saúl, supo que había ido al Carmelo, donde se había alzado un monumento» (I Samuel 15,12). Elías subió al Carmelo: «Elías subió a la cumbre del Carmel y se postró en tierra, poniendo el rostro entre las rodillas" (I Reyes 18,42). Eliseo, discípulo de Elías, permaneció algún tiempo en el monte Carmelo: «De allí subió al monte Carmel, desde donde se volvió a Samaria» (II Reyes 2,25). «Partió, pues, y llegó al hombre de Dios en el monte Carmel» $(4,25)$.

33 Y. Bonnefoy (dir.), Diccionario de las mitologías, Destino, vol. V, Barcelona, 2000, p. 571. 
El Carmelo era la imagen de la belleza y la prosperidad: « ¿Qué bellos son tus pies con las sandalias, hija del noble pueblo! El contorno de tus caderas es una joya, obra de manos de orfebre [...] Tu cabeza, como el Carmelo» (El Cantar de los Cantares 7, 2 y 6). A su vegetación, abundante para Palestina, no solo hace alusión su propio nombre (en hebreo, karmel significa «jardín», «vergel»), sino que también los profetas juegan a menudo con su etimología: «Basán y el Carmelo han perdido su follaje» (Isaías 33,9). «Florecerá y exultará con júbilo y cantos de triunfo; le será dada la gloria del Líbano, la hermosura del Carmelo y del Sarón» $(35,2)$. «Y traeré a Israel a sus pastizales, y se apacentará en el Carmelo» (Jeremías 50,19$)$. «Y estarán en duelo los pastizales de los pastores y secárase la cima del Carmelo» (Amós 1,2). «El Basán y el Carmelo desfallecen y se marchita el verdor del Líbano» (Nahum 1,4).

El Nebo es un monte en la cordillera de Abarim en Transjordania frente a Jericó, desde cuya cima Moisés pudo contemplar la Tierra Prometida antes de morir: «Sube a este monte de Abarim —el monte Nebo, en tierra de Moab, frente a Jericó- y mira desde ahí la tierra de Canán, que voy a dar en posesión a los hijos de Israel; y muere en ese monte a que vas a subir, y reúnete con tu pueblo, como murió Arón, tu hermano, en el Or» (Deuteronomio 32,49-50). Asimismo, una gruta del monte Nebo fue el lugar donde el profeta Jeremías habría ocultado el arca de la alianza, el tabernáculo, y el altar de los perfumes: «el profeta, por revelación divina, mandó que le siguiesen con el tabernáculo y el arca, y salió hasta el monte donde había subido Moisés para ver desde allí la heredad de Dios. Llegado a él, Jeremías halló una gruta a modo de estancia, en la cual introdujo el tabernáculo, el arca y el altar de los perfumes, murando en seguida la entrada» (II Macabeos 2,4-5).

El Hor u Or es un monte cerca de Cadés, en los confines de Edom. Fue precisamente en la cima del monte Hor donde murió Aarón: «Alzando de Cades el campamento, llegó Israel con toda la muchedumbre al monte Or. Yavé habló a Moisés y Arón en el monte Or, que está en los confines de la tierra de Edom, diciendo: "Arón va a reunirse con su pueblo, pues no ha de entrar en la tierra que yo he dado a los hijos de Israel, porque fuisteis rebeldes a mi mandato en las aguas de Meriba. Toma a Arón y a su hijo Eleazar, y sube con ellos al monte Or; y allí que se despoje Arón de sus vestiduras y revista de ellas a Eleazar, su hijo, porque allí se reunirá Arón con los suyos; allí morirá. Hizo Moisés lo que mandaba Yavé, y a la vista de toda la muchedumbre subieron al monte Or. Moisés hizo que se desnudara Arón de sus vestiduras y revistió de ellas a Eleazar, su hijo; y allí murió» (Números 20, 22-29).

Después de ser conquistada la ciudad jebusita de Jerusalén (II Samuel 5,7), Yavé eligió la colina de Sión como lugar de su gloria. El salmista mira a los montes, de los que le llega la ayuda divina: «Alzo mis ojos a los montes, de donde me ha de venir el socorro» (Salmos 121,1). Al final de los tiempos, «el monte de la casa de Yavé será confirmado por cabeza de los montes, y será ensalzado sobre los collados, y correrán a él todas las gentes, y vendrán muchedumbres de pueblos, diciendo: Venid, subamos al monte de Yavé, a la casa del Dios de Jacob, y El nos enseñará sus caminos e iremos por sus sendas, porque de Sión ha de salir la Ley» 
(Isaías 2,1-3). También otros profetas prometen que, en el futuro, Yavé morará en el monte Sión: «Así habla Yavé Sebaot: Yo siento por Sión un amor extremado y un extremado celo. Así habla Yavé Sebaot: Ya me he vuelto hacia Sión y habitaré en Jerusalén, y Jerusalén será llamada la ciudad fiel, y el monte de Yavé Sebaot, el monte santo» (Zacarías 8, 1-3). Y en los Salmos $(48,1)$ leemos: «"El monte de Sión, delicia de toda la tierra, se yergue bello del lado del aquilón, de la ciudad del gran rey"; "alégrase el monte de Sión"» (Salmos 12).

Garizim es un monte situado entre el valle de Siquem y el monte Ebal. Yavé ordenó a las tribus de Israel reunirse en sus laderas y en las del monte vecino, la mitad de cada lado, para escuchar las bendiciones y maldiciones referentes a la observancia de la ley —éstas últimas se leyeron en el monte Ebal- (Deuteronomio 11,29; 27,12; Josué 8,33); y fue la cima del Garizim donde Jotán pronunció una parábola ante los nobles de Siquem (Jueces 9,7).

Después del censo llevado a cabo por David, hijo de Salomón —considerado como una herejía-, Dios castigó a Israel con la peste: «El ángel de Yavé tendía ya su mano sobre Jerusalén para destruirla; pero se arrepintió Yavé del mal y dijo al ángel que hacía perecer al pueblo: "Basta; retira ya tu mano" [...] A la vista del ángel, que hería al pueblo, dijo David a Yavé: "Yo he pecado; pero éstos, las ovejas, ¿qué han hecho? Caiga tu mano sobre mí y sobre la casa de mi padre". Aquel día vino Gad a David y le dijo: "Sube y alza a Yavé un altar en la era de Areuna, el jebuseo"» (II Samuel 24,16-18). El lugar donde David levantó el altar y ofreció holocaustos lo identifica el texto bíblico (II Crónica 3,1) con el monte Moria, en el que Abraham debía sacrificar a su hijo Isaac por mandato de Yavé.

El Tabor es un monte situado en el límite meridional de la Baja Galilea; su forma de cúpula invertida le dio fama desde los tiempos bíblicos, comparable incluso a la de los montes Hermón y Carmelo (Salmos 89,13; Jeremías 46,18). Fue un lugar de culto (Oseas 5,1$)$ y punto de encuentro de los territorios de Zabulón, Isacar y Neftalí (José 19,23, 34). La tradición cristiana sitúa en el Tabor el lugar de la «Transfiguración», por eso desde los primeros siglos de nuestra era se edificaron allí varias iglesias conmemorativas.

En el Nuevo Testamento encontramos también el monte como imagen favorita del lenguaje religioso. Desde una colina Jesús proclama, como lo había hecho con anterioridad Moisés, el nuevo código de la alianza, encabezado por el anuncio de las Bienaventuranzas (Mateo 5,1-12). Del mismo modo, desde un monte eligió a sus doce apóstoles: «Subió a un monte, y llamando a los que quiso, vinieron a Él, y designó a doce para que le acompañaran y para enviarlos a predicar» (Marcos 3, 13-14). Después de la primera multiplicación de los panes, Jesús «subió a un monte apartado para orar» (Mateo 14,23). Otro monte va a ser testigo de la Transfiguración de Jesús ${ }^{34}$ y el

34 «Seis días después tomó Jesús a Pedro, a Santiago y a Juan, su hermano, y los llevó aparte, a un monte alto. Y se transfiguró ante ellos; brilló su rostro como el sol y sus vestidos se volvieron blancos como la luz. Y se les aparecieron Moisés y Elías hablando con El. Tomando Pedro la palabra, dijo a Jesús: Señor, iqué bien estamos aquí! Si quieres, haré aquí tres tiendas: una para ti, una para Moisés y otra para Elías. Aún estaba él hablando, cuando los cubrió una nube resplandeciente, y salió de la nube 
monte de los Olivos ${ }^{35}$, de la angustia mortal; representan estaciones hasta la última altura terrena, el monte Calvario o Gólgota ${ }^{36}$, en el que fue levantada la cruz. Y desde el monte Olivete asciende al cielo: «Diciendo esto y viéndole ellos, se elevó, y una nube le ocultó a sus ojos. Mientras estaban mirando al cielo, fija la vista en Él, que se iba, dos varones con hábitos blancos se les pusieron delante y les dijeron: Varones galileos, ¿qué estáis mirando al cielo? Ese Jesús que ha sido llevado de entre vosotros al cielo vendrá así como le habéis visto ir al cielo. Entonces se volvieron del monte llamado Olivete a Jerusalén» (Hechos de los Apóstoles 1, 9-12).

Asimismo la montaña va a ser testigo de las tentaciones sufridas por Jesús por parte del espíritu del mal: «De nuevo le llevó el diablo a un monte muy alto» (Mateo $4,8)$. También en una montaña cura a los desventurados: «Vino Jesús cerca del mar de Galilea, y subiendo a una montaña, se sentó allí. Se le acercó una gran muchedumbre, en la que había cojos, mancos, ciegos, mudos y muchos otros, que se echaron a sus pies, y los curó» (Mateo 15,29). Asimismo la montaña será testigo de cómo una multitud hambrienta recibe el pan que milagrosamente le proporciona Jesús: «Y comieron todos y se saciaron, y se recogieron de los pedazos que quedaron siete espuertas llenas. Los que comieron eran cuatro mil hombres sin contar las mujeres y los niños» $(15,37-38)$.

\section{MONTAÑAS MÍTICAS}

Según la cosmología hindú y, que sin embargo puede guardar paralelismos en muchas otras formas tradicionales, el centro del Universo está señalado por una montaña simbólica conocida como el Monte Meru o Sumeru: «con sus laderas enjoyadas, orientadas hacia las cuatro direcciones, habitadas en el oeste por serpientes nagas, en el sur por gnomos, en el norte por gigantes terrestres y en el este por músicos divinos, un universo en forma de huevo, y que tenía sobre su cumbre cuadrangular las mansiones regias de los dioses inmortales, cuya ciudad

una voz que decía: Este es mi Hijo amado, en quien tengo mis complacencias; escuchadle. Al oírla los discípulos cayeron sobre su rostro, sobrecogidos de gran temor. Jesús se acercó, y tocándolos dijo: Levantaos, no temáis. Alzando ellos los ojos, no vieron a nadie, sino sólo a Jesús» (Mateo 17,1-8).

35 Colina al este de Jerusalén, frente a la ciudad de Jerusalén (Zacarías 14,4), allende el valle del Cedrón. Y en ella, Jesús eleva su oración al Padre en medio de la angustia de su próxima muerte: «Saliendo, se fue, según costumbre, al monte de los Olivos, y le siguieron también sus discípulos. Llegados allí, díjoles: Orad para que no entréis en tentación. Se apartó de ellos como un tiro de piedra, y, puesto de rodillas, oraba, diciendo. Padre, si quieres, aparta de mí este cáliz; pero no hagas mi voluntad, sino la tuya» (Lucas 22, 39-44). El rey David tuvo que trepar las pendientes del Monte de los Olivos cuando huía de Absalón: «Subía David la pendiente del monte de los Olivos» (II Samuel, 15,30). «Dichos los himnos salieron para el monte de los Olivos" (Marcos 14,26). Los Hechos de los Apóstoles $(1,12)$ localizan en el monte de los Olivos la Ascensión de Jesús: «Entonces se volvieron del monte llamado Olivete a Jerusalén».

${ }^{36}$ El nombre proviene del arameo golgota, que significa «calavera» o «sitio de la calavera»: «Llegando la sitio llamado Gólgota, que quiere decir el lugar de la calavera» (Mateo 27,33). La tradición cristiana sitúa el lugar al oeste de la ciudad de Jerusalén, y por la traducción al latín de Lucas 23,33 también fue conocido como Calvario. 
llena de torres se conocía como Amaravati, "la ciudad inmortal"»37. Según la tradición el Monte Sumeru está emplazado en la cordillera del Himalaya:

«De acuerdo a la cosmología hindú cuatro continentes en forma de pétalo de loto se extienden desde el monte Meru como su centro y más allá de éstos hay siete mares en forma de anillo y continentes en forma de anillo en el universo más amplio. El monte Meru se levanta hacia el cielo como el contenedor de las semillas de loto del mundo. Como un axis mundi, esta montaña, enraizada en la profundidad del inframundo, se levanta hacia lo alto a través de los reinos del cielo, donde se extiende para acomodar las ciudades de todos los dioses. Es interesante resaltar que el Meru no tiene pico, ya que los textos geográficos de los Purânas están de acuerdo en que el Meru es más ancho en la parte de arriba que en su parte de debajo de acuerdo con su prototipo de contenedor de semillas y la conciencia politeísta que acomoda a muchos dioses arriba. El Meru tiene cuatro lados de colores distintos (varnas) y está franqueado por cuatro montañas direccionales. Por encima del Meru está la estrella polar y a diario el sol conduce su carruaje alrededor de la montaña. El Ganges celeste en su bajada hacia la tierra primero toca la cima del Meru y luego se divide en cuatro ríos que desaguan en las cuatro direcciones cardinales para regar la tierra» 38 .

Por su parte, la cosmología búdica, sitúa al Meru en el punto central de un pequeño universo formado por un grupo de océanos, montañas y continentes habitados por diversos seres:

«En la base del monte Meru, en las grutas oceánicas y en las cavidades de los peñascos viven los asuras o titanes, que ocupan cuatro inmensas ciudades, cada una de ellas gobernada por un rey. Los cuatro primeros niveles del monte Meru se encuentran respectivamente ocupados por los nâga, las deidades acuáticas guardianas de los tesoros, y por diversas categorías de semidioses [...] El cuarto nivel está ocupado por los cuatro reyes guardianes de las direcciones [...] Ésta es la puerta de entrada a los dominios divinos, la primera de las seis residencias de los dioses del deseo. La segunda, la morada de los treinta y tres, ocupa la cima del monte Meru, junto al palacio de Indra. El resto de residencias divinas, es decir, las cuatro últimas residencias de los dioses del dominio del deseo [...] las diecisiete residencias de los dioses del dominio de la forma pura [...] y las cuatro esferas de los dioses de lo sin-forma [...] se sitúan en el espacio que se encuentra por encima de la montaña axial ${ }^{39}$.

No sólo el monte Meru, punto culminante del planeta, la mayoría de las montañas de la India eran adoradas por los pueblos que vivían en sus pendientes y en su falda: «Montañas de Vindyah, de Satpurah, de Aravalli, de Nilagherry, todas tenían sus adoradores. En las tierras bajas, donde los fieles no tenían montañas que contemplar, construían templos que representaban las veneradas cimas del monte Meru» 40

37 J. Campbell, Las máscaras de Dios. Mitología primitiva, Alianza, Madrid, 2000, p. 181.

38 M. Eliade (ed.), The Encyclopedia of Religion, Simon and Shuster Macmillan, vol. 9, Nueva York, 1995, p. 130.

39 P. Cornu, Diccionario de budismo, Akal, Madrid, 2004, p. 126.

40 E. Reclús, la montaña, F. Sempere editor, Valencia, s/f, pp. 178-179. 
En los confines de Macedonia y Tesalia, y a lo largo de la costa del mar Egeo, del que está separado sólo por una estrecha franja litoral, se eleva la altanera mole del Olimpo, «de innumerables pliegues», el monte por excelencia en la imaginación de los pueblos de occidente y la más bella de las montañas sagradas de la antigua Grecia. Desde épocas muy remotas se creía que el Olimpo era la morada de los dioses, capitaneados por Zeus, y de ahí el epíteto «olímpicos» que suele dárseles. Este concepto de «Olimpo» fue diferenciándose gradualmente de la idea del monte propiamente dicho, y llegó a pensarse más o menos vagamente que los dioses habitaban en el cielo que cubre el monte Olimpo. Homero ${ }^{41}$ describe su morada feliz en los siguientes términos: "Cuando hubo hablado así se marchó Atenea, la de los brillantes, al Olimpo, donde dicen que está la morada siempre segura de los dioses, pues no es azotada por los vientos ni mojada por las lluvias, ni tampoco la cubre la nieve. Permanece siempre un cielo sin nubes y una resplandeciente claridad la envuelve. Allí se divierten durante todo el día los felices dioses» (Odisea VI, 40-46).

Nysa, la montaña feliz, el lugar de la infancia de Dionisio y de su educación, es un equivalente del Kailâsa, del paraíso terrenal. Los griegos creyeron hallar por todas partes la montaña de Nysa. «Existe una cierta Nisa, una montaña muy alta, exuberante de bosques, lejos de Fenicia» ${ }^{42}$.

El Parnaso es uno de los montes más altos de Grecia, situado en las estribaciones del Pindo, en cuya ladera sur se encontraba el famoso oráculo de Apolo, y próximo también a la fuente Castalia, cuyas aguas tenían la facultad, según se decía, de proporcionar la inspiración a quien las bebía. Según los mitos más antiguos, el Parnaso era la morada de Dionisio y de su orgiástico séquito de Ménades, ninfas y sátiros, mientras que el Helicón y Pieria eran la residencia favorita de las Musas; más tarde, fue considerado la morada de Apolo y de las Musas, y la sede de la poesía y la música. Por eso se puso el nombre de Montparnasse (Monte Parnaso) a la pequeña colina situada en la orilla izquierda del Sena, en la que se encontraba la universidad y el centro cultural de París.

Por su característica forma y por su situación junto al mar, el monte Atos atraía la atención de los navegantes desde los tiempos más remotos, y, en torno a él, nacieron extrañas leyendas. Homero menciona el monte Atos en un famoso pasaje donde describe poéticamente las regiones sobrevoladas por la diosa Hera: «Hera abandonó de un salto la cumbre del Olimpo, y, en Pieria poniendo el pie y en la amable Amatia, se lanzó por encima de los nivosos montes de los tracios, pastores de corceles, por encima de sus más altas cumbres, sin hollar con entrambos pies la tierra. Y desde el Atos se encaminó por encima del mar alborotado, y a Lemnos llegaba» (Ilíada 14,226-230).

41 Una de las notas características del dios en Homero es la predilección por las cumbres más elevadas; sobre los picos del Ida, o sobre el más alto punto del Olimpo es donde Zeus se siente complaciente.

42 A. Bernabé (ed.), Himnos homéricos. La Batracomiomaquia, Gredos, Madrid, 1978, p. 40. Véase A. Daniélou, ob.cit., pp. 192-195. 
